\title{
Gender analysis and training needs assessment of class 4 staff in a tertiary health care institute
}

\author{
Priyanka U. Honavar*, Padmaja Y. Samant, Swati B. Bhosle
}

Department of Obstetrics and Gynaecology, Seth GS Medical College and KEM Hospital, Mumbai, Maharashtra, India

Received: 07 May 2021

Accepted: 21 May 2021

\author{
*Correspondence: \\ Dr. Priyanka U. Honavar, \\ E-mail: drpriyankahonavar13@gmail.com
}

Copyright: (c) the author(s), publisher and licensee Medip Academy. This is an open-access article distributed under the terms of the Creative Commons Attribution Non-Commercial License, which permits unrestricted non-commercial use, distribution, and reproduction in any medium, provided the original work is properly cited.

\begin{abstract}
Background: A health care team comprises of doctors, nurses, paramedical staff, medical assistants, administrators and support staff or class 4 workers. Each individual has a role in the execution of proper health care delivery to the patients. Obstetrics and gynecology is a dynamic branch requiring urgent attention in most cases right from admission to discharge. Delivery of prompt treatment is possible with better training and coordination of the health care team. In a tertiary care institute, referred patients have more critical health problems and need urgent assistance by well-trained staff. On the other hand, in a smaller set up with less human resource, agile and well-trained support staff would be an asset to overcome the limitations. Better-trained staff means less loss of man-hours from injuries and illnesses, less medico legal liabilities, reduced maintenance cost of equipment and less expenditure on health-related issues of staff. We conducted an interview based cross sectional observational cohort study of the situation and an assessment of needs for skill building of support staff in a tertiary care hospital. At the end, we propose a structured training program suitable to the local needs that can be conducted by experienced peers, technical staff and medical personnel. We studied unmet training needs of the staff and gender related issues.

Methods: A questionnaire based cross sectional study involving 92 class 4 workers in the department of obstetrics and gynecology in a tertiary care hospital was conducted comprising questions regarding their demography, work profile, training, needs and problems faced. Key informants in the relevant area were also interviewed.

Results: Graphical representation of the responses received has been made. Professional work profile, health issues, gender issues, training need of any specialized training has been highlighted.

Conclusions: As an important part of the health care team, this study has brought out issues related to health especially occupational health, needs for training, hurdles faced at work amongst class 4 staff working in the department of obstetrics and gynecology.
\end{abstract}

Keywords: Obstetrics, Gynecology, Training, Workers, Health, Gender, Health care workers

\section{INTRODUCTION}

A well-informed and empowered workforce is more efficient and hence more satisfied than an untrained workforce. This applies to health care team more aptly than any other as patients' lives are at stake. Healthcare team is defined as a range of health care workers e.g., physicians, physician extenders, nurses, medical assistants and those providing ancillary and diagnostic services e.g., radiology and lab technologists, physical therapists, nutritionists, psychotherapists, massage therapists who provide diagnostic and therapeutic procedures on a patient. ${ }^{1}$ The last wrung of the staff includes attendants, cleaners-class 4 employees who maintain the workplace. In public sector health care facilities, support and cooperation of staff like conservancy, sanitation staff and attendants at work in wards, outpatient departments and operation theaters cannot be underestimated. Patient mobilization, hygiene and cleanliness cannot be maintained without their cooperation. It is important that 
these staff members be trained for the job they are hired for and trained in certain basic communication methods.

Most of the class 4 employees work in shifts, they are exposed to dangers of repetitive strain injuries (mainly lower backache) due to patient-lifting and transportation, long hours of standing duties and bad work postures. ${ }^{2}$ They are in touch with various chemicals as part of their work of cleaning and disinfection. These can cause short term and long-term health problems if the handlers are not trained in safe handling of the chemicals. Class 4 employees can be faced with multiple health and workrelated issues themselves and at the same time, can risk patients' safety in various ways. Incidence of infectious diseases is high in this cadre due to occupational exposure and lack of information on prevention. ${ }^{3}$

In a tertiary care institute, referred patients have more urgent and critical health problems and need urgent assistance by well-trained staff. On the other hand, in a smaller set up with relatively less human resource and advanced facilities, agile and well-trained support staff would be an asset to overcome the limitations. From hospital management point of view, training of support staff has numerous benefits. Better trained staff means less loss of man-hours from injuries and illnesses, less medico legal liabilities, reduced maintenance cost of equipment and less expenditure on health related issues of staff. In larger institutes, since advanced interventions are done more frequently, new equipment is put in use, handling and maintenance training is required to be done frequently. We conducted an interview based cross sectional observational study of the situation and assessment of needs for skill building of support staff in a tertiary care hospital. Our focus is on obstetrics and gynecology department as it has critical care area like labor ward, in addition to surgical, antenatal and postnatal care wards, an in-house laboratory, outpatient department and operation theatres. In postnatal wards, presence of neonates causes the number of patients to be double that of the bed strength. They also require closer attention and service from nursing staff. Hygiene and patient safety require more vigilance. Gender understanding and sensitivity is a need among employees working in this area as inexperienced mothers struggle with feeding their babies.

At the same time, vulnerabilities of a large number of women employees need to be understood and efforts must be directed at their empowerment. Gender blind work allotment and human resource management needs to be improved. We studied unmet training needs of the staff and gender related issues. Interviews with key informants also added to management issues that may be commonly faced during day-to-day work. At the end we recommend modules and propose a structured training program that can be conducted by experienced peers, technical staff and medical personnel suitable to the local needs and Indian public health care facility needs.
Aims and objectives was to establish the need to train hospital assistant staff (class 4 staff) in patient care, communication and equipment handling before induction and to understand the workplace situation of the class 4 staff, study comprehension among the class 4 staff with respect to their occupational roles and to derive the unmet training needs of the class 4 staff.

\section{METHODS}

The study was a cross-sectional, questionnaire-based study. The study was carried out at the department of obstetrics and gynecology Seth GS medical college and KEM hospital, a tertiary care, teaching hospital in Mumbai, India. The study was carried out for 3 months from October 2019 to December 2019.

\section{Inclusion criteria}

All class 4 staff members working in the department regardless of age or gender. Officer in charge of the staff, assistant dean and nursing in-charges were interviewed as key informants were included in the study.

\section{Exclusion criteria}

Those who refuse to consent were excluded from the study.

Purposive sampling was done and 92 members of the class 4 workers were enrolled in the study. After valid, informed, written consent, a structured pre-validated questionnaire was administered to participants. Interviews of key informants were conducted by the research team. The study was initiated after approval by the ethics committee of the institution.

\section{Data collection and statistical analysis}

The questionnaire was generated as per the local needs and circumstances. Questionnaires for both- participants and key informants were validated by subject experts including gender, labor, ethics and field experts.

Questions assessed participants demographics, prior training, training after employment, professional difficulties faced, health and health care seeked, occupational health screen, familiarity with the work profile including interaction with patients, handling of equipment, waste and assessment of need for training and understanding its implication at work.

Data was analyzed using SPSS software and tables and graphical representation of the various parameters was done. We sought participants' suggestions about solutions to the difficulties routinely faced, possible methods for improvisation and need for training. Responses to questions in the questionnaire for key informants were analyzed in a similar manner. 


\section{RESULTS}

\section{Participants}

Demography: 72 women and 20 men participated in the study and their duration of service ranged from one month to 35 years. 17 men and 8 women were married. 22 women were widowed or separated. There were employees of different origin however, locals were in the majority (Maharashtrian).

The 69 had owned houses, 20 lived in rented houses and 3 in quarters provided by the hospital authorities. The distribution is based on work experience, address of permanent residence and the rank on the waiting list for accommodation.

The $11 \%$ had completed their primary school education, $67 \%$ completed their secondary school education (grade 10 ), $1 \%$ was graduate and postgraduate each (worked as part time contractual employee or at higher posts like supervisor or Mukadam) and the rest $20 \%$ were illiterate all employed as cleaning or housekeeping staff.

Male employees 3 out of 20 and 8 out of 72 female employees were contractual. Among men, 9 were employed as ward boys, 8 as sweepers, 3 as dressers. Mukadam is a post which has added responsibility of supervision of work done by other employees. Men are given the responsibility as Mukadams. Men were hired for tasks like dresser, operation theatre assistants which are semi-skilled tasks. Among women, ayahs and sweepers were the two categories. Among women, 36 were ayahs, 36 females were sweepers. Women reported that they did generally variety of work including sweeping, cleaning, serving food, taking calls etc. There is clearer divide of work among males. Even in operation theatres where only women are operated, conventionally men are posted as operation theater servants, women servants in operation theaters only clean corridors, they are not given patient or equipment related work. Conventional practice and heavy work involved e.g., handling of equipment, lifting patients in the theaters were the reasons given for the same.

There were no promotions except in 2 persons (both males).

It is seen that work that is understood to involve higher responsibility and skill is given only to men, though none underwent pre-employment training of any sort for the post.

Uniform: Saree is a conventional dress for the participant women employees. With the kind of work done, salwar kameez is a more convenient dress that is less likely to be contaminated. Dominant gendered practices at work prevail.

Infection prevention practices: All participant employees reported use of gloves and masks while working with biohazardous material. They used latex gloves for all work. There is need to provide heavy duty utility gloves for cleaning. All reported using aprons.

Table 1: Health issues.

\begin{tabular}{|lll|}
\hline Health issue & Number & Percent $(\%)$ \\
\hline Respiratory allergies & 11 & 12 \\
\hline Infective hepatitis & 1 & 1.08 \\
\hline Hypertension & 6 & 6.5 \\
\hline Asthma & 3 & 3.25 \\
\hline Cataract & 1 & 1.08 \\
\hline Psychiatric illness & 1 & 1.08 \\
\hline Ischemic heart disease & 1 & 1.08 \\
\hline $\begin{array}{l}\text { Rheumatic heart } \\
\text { disease }\end{array}$ & 1 & 1.08 \\
\hline Diabetes mellitus & 5 & 5.4 \\
\hline Menstrual disorders & 3 & 4.1 \\
\hline Joint pains & 1 & 1.08 \\
\hline
\end{tabular}

No employee reported tuberculosis, HIV or other infections. No employee reported addictions. Possible reasons for this may be familiarity with research team and stigma. Also gender of researchers (all females) may have influenced the answers.

\section{Work related health problems}

Allergies were the largest reported problem. Respiratory allergies were dominant complaint probably due to not wearing masks during sweeping and due to chemical disinfectants.

Due to shortage of staff, employees faced difficulty in transporting pregnant patients and surgical patients. Joint and muscular problems were not dominantly reported, though one employee complained of joint pains and others had back sprains at some point of their career. Due to shortage of staff, employees faced difficulty in transporting pregnant patients and surgical patients. In spite of provision of rollers, attendants avoid using the same to shift patients. This increases risk to patients as well as musculoskeletal injuries among employees.

Needle stick injuries were not reported as probably they were thought as innocuous events. Also, extensive use of needle burners and awareness among doctors and nurses due to regular training about sharps disposal, incidence of needle stick injuries has reduced. 57 employees reported having taken tetanus toxoid. Hepatitis vaccine was reported to be not taken by anyone. Post exposure prophylaxis was not reported by anyone.

\section{Health checkups and treatment facilities}

Pre-employment health check-up is done as in most public sector institutes. Except 2 women and 1 male employee (employees on contract basis), rest all permanent 
employees had undergone medical examination before being hired. Post-employment, none have undergone routine health checkup. This is partly due to lack of such schemes and partly due to the fact that employees get free investigations and treatment for health problems.

All workers have health cards mentioning leaves taken for illness, summary of diagnosis, admission and treatment. About $70 \%$ of class 4 employees have availed the municipal health insurance scheme.

Salary structure: There is gender divide in salary structure: The difference is significant at the lower end of scale $(\mathrm{p}<0.05)$ among junior and contractual staff. Men received salary ranging from 10,000-36,000 in rupees per month whereas women received from 5500-27000 per month.

\section{Pre- and post-employment training}

None of the employees have undergone pre-employment training. Three out of 92 employees stated that they have undergone post-employment HIV related training i.e., biomedical waste handling and post exposure prophylaxis.

Communication with patients: There is no training on communication for class 4 workers. OT servants stated that they do not communicate with patients. OPD and ward servants communicate with the patients.

Recognition of emergency, medico legal cases and maintaining patient confidentiality: Outpatient department servants understand emergency by observing and due to medicolegal cases they understood what confidentiality is. Most employees depended on doctors or nurses for identifying emergencies. The employees stated that they learned about handling patients and equipment from their senior colleagues. Employees acquired knowledge of chemical disinfectants, biomedical waste handling from their senior colleagues or nurses during work.

Infection prevention: They were aware of importance of wearing gloves and masks while handling grossly contaminated material, but they did not have knowledge of microscopic contamination, fomites or airborne infections.

Expectations: $70 \%$ employees wished to undergo regular training regarding their work profile, occupational hazards, waste handling and management, patient safety, emergencies and orientation to medical equipment for better handling. Half of the employees were interested in knowing about communicable diseases pertaining to their work profile. $25-30 \%$ employees liked to resolve issues with their sanctioned or medical leaves. $18 \%$ had no expectations at work and felt contented.

\section{Key informants}

Eleven key informants were interviewed including 9 staff nurses heading the antenatal, postnatal, labor ward, waiting ward, gynecology ward, post-operative wards and obstetric and gynecological operation theatres of the department of obstetrics and gynecology, the assistant dean and the officer in charge of the staff. They head, assign work and supervise the class four workers deputed in their areas and also form a part of the policy making team. Average age group of the key informants was 52 years with an average experience in their field of 30 years.

Formal administrative training was received only by the assistant dean and three head nursing staff. All nursing heads received regular training in infection control, sanitation, waste disposal and occupational health organized by the institution at regular intervals. However, all claimed to have learned about respective ward management especially equipment care and maintenance with time or from device company authorities. Officer incharge of the staff reported having learnt respective area work as a beginner from guidance by senior colleague, experience over time or from staff nurse and never received any formal training. They also instruct their workers to learn work from their designated area while working.

None of the supervisory staff are sensitized about labor laws. Administrative officers have been trained on the job with inputs from seniors and personnel officers. Job vacancies are filled as per the need. Duties are assigned as per post wise duty list. Periodic trainings have been conducted on HIV and TB infection prevention and control by microbiology department. Psychiatry department has conducted stress management workshop. Dispute resolution or any employee related issues are initially dealt by the respective department heads and nurses in charge. Work related health problems are noted from the point of view of absenteeism or paid leaves if due like the one for tuberculosis. Expenditure is reimbursed, Insurance scheme is available. Municipal corporation has also started an employee insurance scheme recently wherein the employees and their dependents are given free healthcare. Contractual employees do not have leave privileges. Permanent employees have weekly one leave in addition. Difference in the salary slabs of employees of the same post is due to their years of experience and leaves taken over and above their sanctioned ones; most of them being women who take leave due to their domestic responsibilities. Maternity leave of 180 days is sanctioned. Promotion is refused by women employees as it demands handling responsibilities, managing other employees, arranging their duties and controlling their work. This is an important gender issue as women in these positions are not empowered to handle responsibilities and prefer to follow instructions. Employee training is limited to HIV and TB control sensitization and sensitization about prevention of sexual harassment at workplace.

\section{DISCUSSION}

A study published by Gore et al in 2013 about class 4 municipal hospital workers showed that $50.9 \%$ had some or other health problem. $68.7 \%$ employees had 
musculoskeletal disorders, $45.3 \%$ had gastrointestinal problem, $38.6 \%$ had skin diseases, $28.2 \%$ had injuries, $23.9 \%$ had respiratory diseases, $25 \%$ females had gynecological problems and all women were anemic. $9.2 \%$ had hepatitis, $4.2 \%$ had tuberculosis, $2.45 \%$ were HIV positive. $^{4}$ Psychological problems and addictions are abundant in this category. ${ }^{4}$ So, a variety of diseases were noted in this cohort as in our study, which needs to be addressed timely. They also found that nearly $61 \%$ class 3 class 4 employees took no action for injuries sustained at work. Musculoskeletal injuries are highest in health care workers, more than 7 times that of other industries. ${ }^{5}$ This implies urgent need for formal and regular training of these workers. Study conducted in state of Kerala that has almost $100 \%$ literacy, nursing attendants had the least training among all categories of workers. ${ }^{6}$ U.S. hospitals recorded 6.4 work-related injuries and illnesses for every 100 fulltime employees in 2013, compared with 3.3 per 100 fulltime employees for all US industries combined. Safe patient handling programs can help educate and prevent injuries such as musculoskeletal disorders (MSDs). ${ }^{7}$

Table 2: Training needs.

\begin{tabular}{|c|c|c|c|c|}
\hline Work & Level & $\begin{array}{l}\text { Supervision } \\
\text { required }\end{array}$ & Type of training Required & $\begin{array}{l}\text { Commonly } \\
\text { assigned to }\end{array}$ \\
\hline Taking calls & Unskilled & No & $\begin{array}{l}\text { Understanding of emergency, } \\
\text { confidentiality }\end{array}$ & Female \\
\hline Connecting gadgets & Semiskilled & Yes & $\begin{array}{l}\text { Basics of equipment handling, } \\
\text { maintenance }\end{array}$ & Male \\
\hline Sterilization & Semiskilled & Yes & Hygiene and technical information & Male \\
\hline $\begin{array}{l}\text { Packing linen and } \\
\text { instruments, } \\
\text { autoclaving }\end{array}$ & Semiskilled & Yes & $\begin{array}{l}\text { Hygiene and technical } \\
\text { information }\end{array}$ & Male \\
\hline $\begin{array}{l}\text { Giving position to } \\
\text { patients }\end{array}$ & Semiskilled & Yes & Ergonomics & $\begin{array}{l}\text { Female in ward, } \\
\text { male in theater }\end{array}$ \\
\hline Serving food & Unskilled & No & Types of diet, hygiene & Female \\
\hline $\begin{array}{l}\text { Helping in } \\
\text { operation theater }\end{array}$ & Semiskilled & Yes & Basics of equipment handling & Male \\
\hline Disinfection & Unskilled & Yes & Biomedical waste handling & Male and female \\
\hline $\begin{array}{l}\text { Washing soiled } \\
\text { linen }\end{array}$ & Unskilled & No & Biomedical waste handling & $\begin{array}{l}\text { Female in ward, } \\
\text { male in theater }\end{array}$ \\
\hline Waste disposal & Unskilled & Yes & Biomedical waste handling & Male \\
\hline Moving equipment & Unskilled & No & $\begin{array}{l}\text { Ergonomics, basics of equipment } \\
\text { handling }\end{array}$ & Male \\
\hline $\begin{array}{l}\text { Transporting blood } \\
\text { samples }\end{array}$ & Unskilled & No & $\begin{array}{l}\text { biohazardous material handling, } \\
\text { confidentiality }\end{array}$ & Female \\
\hline $\begin{array}{l}\text { Transporting } \\
\text { material from stores }\end{array}$ & Unskilled & No & Ergonomics & Male \\
\hline Shifting patients & Unskilled & Yes & Ergonomics & $\begin{array}{l}\text { Female in ward, } \\
\text { male in theater }\end{array}$ \\
\hline Making beds & Unskilled & No & biohazardous material handling & Female \\
\hline Cleaning patients & Unskilled & Yes & Hygiene, biohazardous material handling & Female \\
\hline Cleaning wards & Unskilled & No & Hygiene, biohazardous material handling & Male and female \\
\hline Autoclaving & Semiskilled & Yes & $\begin{array}{l}\text { Basics of equipment handling, } \\
\text { maintenance, practical technical training }\end{array}$ & Male \\
\hline
\end{tabular}

It was observed in our study that the employees learn most tasks from their peers during service. Pre induction training is an unmet need. Psychological safety, accountability, teamwork and communication and negotiation are the work culture components of safe and effective healthcare as stated by Institute for healthcare improvement. ${ }^{8}$ These have to be taken into account while hiring and training staff.

The training should take place at induction as well as in service and should later be specialized depending on the area they serve in. Universal training will generate interest and create level field for women in service.

\section{Common works, gender preference and training needs that emerged from our study}

There are numerous models available and are implemented world over and even in corporate hospitals in this country. ${ }^{9}$ In the North Ireland model, the modules are as follows: Protection of vulnerable adults incorporating child protection, moving and handling, infection prevention and control, first aid, fire safety and food hygiene. These take 
place on induction and annually with supplement training e.g. e-learning in between.

Topp SM et al noted that though current trainings help improve their skills and improve overall quality of a health system; numerous preoccupations cause these to take a backseat. ${ }^{10}$

The recommended best practices include: organizing framework for services, creation of interactive training programs for different learning styles for preparedness of employee, personalizing information so it is specific to a given health system, consideration of employee demands beyond training, vigilance by policy makers and evaluation. ${ }^{10}$ With most of the staff having no more than secondary school education, the need of Indian healthcare systems is to have basic structured training at induction in all specialties and hospital areas, periodic refreshers and modules for aspects like infection control, disinfection, equipment handling and safety at work should be implemented. Availability of information and education material with illustrations and gender equality and equity should be ensured in service. As our study has shown there are numerous demands and expectations beyond training which should be addressed so that the workforce feels empowered

\section{Limitations}

Small sample size limited to one department.

\section{CONCLUSION}

The results of this study demonstrated that conventional gender biased work distribution and salary difference should be abolished and should be based on skill, experience and scope of work. Training and regular sensitization of skill and knowledge that would cover aspects such as ergonomics, patient and employee safety, communication skills, waste management, post exposure prophylaxis, recognition of medical emergencies or disasters is a must. The key informants should have frequent drills or training regarding labor and disaster management and 'training the trainer' programs. The valuable suggestions from the participants and feedback from the informants should be considered to understand the basis of training modules in future. Institutional policies keeping in mind labor laws must be developed and implemented. Once this is followed, further studies at timely intervals can be taken up to see the change and efficiency in patient health care delivery and also to update further need for training as time passes. Having identified the commonly faced hurdles, adequate training will be reflected in the work place behavior and will definitely have a positive impact on patient care delivery.

\section{ACKNOWLEDGMENTS}

Authors would like to thank all the participants, validators and reviewers of this study for their time and inputs.

Funding: No funding sources

Conflict of interest: None declared

Ethical approval: The study was approved by the Institutional Ethics Committee

\section{REFERENCES}

1. Medical-dictionary. The free dictionary Pennsylvania (US): Farlex, Inc.; c2003-2021. Available at: https://medical-

dictionary.thefreedictionary.com/health+care+team. Accessed on $1^{\text {st }}$ January 2020.

2. Kulkarni G K. Health of health care professionals. Indian J Occup Environ Med. 2006;10:95-6.

3. Orji EO, Fasubaa OB, Onwudiegwu U, Dare FO, Ogunniyi SO. Occupational health hazards among health care workers in an obstetrics and gynaecology unit of a Nigerian teaching hospital. J Obstet Gynaecol. 2002;22(1):75-8.

4. Gore HD, Shelke AD, Kembhavi RS, Singru SA, Gore VH, Pandve HT. Working Environment and Occupational hazards in class IV employees in tertiary care hospital, Mumbai. Global res analysis. 2013;2(3):146-8.

5. Chhabra S. Health hazards among health care personnel. J Mahatma Gandhi Inst Med Sci. 2016;21:19-24.

6. Saroji V. Awareness and Practice of Standard Precautions among Kerala State Health Services Personnel in Neyyatinkara Taluk. 2014. Available at: dspace.sctimst.ac.in/jspui/bitstream/123456789/2477/1/ 6461.pdf. Accessed on $1^{\text {st }}$ January 2020.

7. Occupational Safety and Health Administration, U.S Department of Labor, Safe Patient Handling Programs. Available at: https://www.osha.gov/SLTC/etools/hospital/hazards/erg o/ergo.html\#training. Accessed $1^{\text {st }}$ January 2020.

8. Frankel A, Haraden C, Federico F, Lenoci-Edwards J. A Framework for Safe, Reliable, and Effective Care. White Paper. Cambridge, MA. Institute for Healthcare Improvement and Safe and Reliable Healthcare. 2017;430.

9. Guidance on Mandatory Training for Providers of Care in Regulated Services. The Regulation and Quality Improvement Authority. Northern Ireland. 2010.

10. Topp SM, Abimbola S, Joshi R, Negin J. How to assess and prepare health systems in low- and middle-income countries for integration of services-a systematic review. Health Policy Plan. 2018;33(2):298-312

Cite this article as: Honavar PU, Samant PY, Bhosle SB. Gender analysis and training needs assessment of class 4 staff in a tertiary health care institute. Int $\mathbf{J}$ Reprod Contracept Obstet Gynecol 2021;10:2275-80. 